\title{
PENGEMBANGAN APLIKASI DIABETES FOOT ULCER ASSESSMENT SCALE (DFUAS) PADA SMARTPHONE
}

\author{
Andi Minhajuddin ${ }^{1}$, Saldy Yusuf ${ }^{2}$, Yuliana Syam² \\ ${ }^{1}$ Mahasiswa Program Studi Magister Ilmu Keperawatan Universitas Hasanuddin, Makassar \\ ${ }^{2}$ Dosen Fakultas Ilmu Keperawatan Universitas Hasanuddin, Makassar \\ saldy_yusuf@yahoo.com
}

\begin{abstract}
ABSTRAK
Tujuan: Melakukan pengembangan aplikasi smartphone Diabetic Foot Ulcer Assessment Scale (DFUAS) pada penilaian Luka Kaki Diabetes (LKD). Metode: Desain penelitian yang digunakan adalah perencanaan dan penelitian pengembangan (Design and Development Research). Melakukan pengembangan DFUAS paper based menjadi aplikasi DFUAS pada smartphone. Hasil: Pengembangan aplikasi DFUAS paper based menjadi aplikasi DFUAS pada smartphone, menghasilkan aplikasi yang memiliki beberapa fitur. Fitur yang tersedia pada aplikasi DFUAS hasil pengembangan diantaranya adalah fitur login, menu utama (home), tambah data pasien, pengkajian pasien, tampilkan data dan memunculkan grafik hasil pengkajian. Kesimpulan: Aplikasi DFUAS pada smartphone memiliki keunggulan bila dibandingkan dengan DFUAS paper based. Berbagai fitur yang terdapat pada aplikasi DFUAS pada smartphone menjadi kelebihan. Meskipun demikian masih dibutuhkan pengembangan lanjut dan penelitian sebelum aplikasi ini digunakan secara umum..
\end{abstract}

Kata kunci: Smartphone, Pengkajian luka, DFUAS, Luka Kaki Diabetes

\section{ABSTRACT}

Objective: To develop a smartphone application for the Diabetic Foot Ulcer Assessment Scale (DFUAS) in the assessment of Diabetes Foot Ilcer (DFU). Method: The research design used is planning and development research (Design and Development Research). Perform paper-based DFUAS development into the DFUAS application on smartphones. Results: Development of the paper-based DFUAS application into the DFUAS application on smartphones, resulting in applications that have several features. The features available in the DFUAS application are the login feature, main menu (home), adding patient data, patient assessment, displaying data and displaying graphs of assessment results. Conclusion: DFUAS application on smartphones has advantages when compared to DFUAS paper based. The various features found in the DFUAS application on smartphones are an advantage. However, further development and research are still needed before this application is used in general.

Keywords: Smartphone, wound assessment, DFUAS, Diabetes foot Ulcer

\section{PENDAHULUAN}

Luka Kaki Diabetes (LKD) merupakan komplikasi yang sering dijumpai pada pasien Diabetes Mellitus (DM). Hal ini disebabkan karena keadaan hiperglikemia yang berlangsung secara terus-menerus, terjadinya neuropati, buruknya vaskularisasi dan kekebalan tubuh yang menurun. Sekitar $15 \%$ dari penderita DM mengalami LKD (Lim, Ng, \& Thomas, 2017). Angka kejadian LKD yang ditemukan di Indonesia bagian timur 
tidak jauh berbeda dengan jumlah ini, yaitu sebesar 12\% (Yusuf et al., 2016).

Salah satu hal terpenting dalam penyembuhan LKD adalah dilakukannya evaluasi proses penyembuhan dengan menggunakan instrumen penilaian. Tujuannya agar praktisi dapat mengevaluasi intervensi perawatan yang telah dilakukan (Chaiteerakij et al., 2016). Terdapat bebeberapa instrumen yang dapat digunakan untuk melakukan evaluasi penyembuhan luka, diantaranya klasifikasi PEDIS (Perfusion, Extent, Depth, Infection and Sensation), Meggit-Wegner Classification, University of Texas (UT), dan Bates-Jansen Wound Assessment Tool (BWAT) (Rasyid, Yusuf, \& Tahir, 2018). Akan tetapi secara khusus untuk mengevaluasi penyembuhan LKD dapat digunakan The New Diabetic Foot Ulcer Assessment Scale (DFUAS). DFUAS terdiri atas 11 item pertanyaan, mulai dari kedalaman, ukuran, penilaian ukuran, peradangan, perbandingan jaringan granulasi, jeis jaringan nekrotik, perbandingan jaringan nekrotik, perbandingan slough, maserasi, tipe tepi luka, dan tunneling (Arisandi et al., 2016).

$$
\text { Penggunaan DFUAS sebagai }
$$

instrumen penilaian penyembuhan LKD di Indonesia masih terbatas di kalangan praktisi luka yang pernah mengikuti pelatihan terkait penggunaan DFUAS. Saat ini penggunaan DFUAS masih berupa paper based, dan diharapkan dapat dikembangkan menjadi sebuah aplikasi smartphone. Hal ini perlu didorong, mengingat penggunaan aplikasi smartphone mampu menjadi solosi akan kurangnya infrastruktur saat ini. Selain itu penggunaan aplikasi pada smartphone dinilai dapat menekan biaya. Selain ada dimana-mana, penggunaan smartphone dinilai relatif mudah dan gampang digunakan (Wang et al., 2017).

Smartphone dapat dimanfaatkan dalam berbagai aspek dalam dunia kesehatan, seperti perawatan pasien, melakukan pendidikan kesehatan, melakukan penilaian pasien, serta melakukan komunikasi profesional (Liu et al., 2016). Penggunaan aplikasi smartphone dalam praktik kesehatan, diyakini bisa memberikan hasil lebih baik. Dalam dunia keperawatan, smartphone dapat dijakan alat pengkajian tanpa kontak langsung, penggunaannya mudah, dapat menilai perkembangan luka pasien, dapat digunakan saat melakuakan kunjungan rumah (Wang et al., 2017). Manfaat yang tak kalah penting, smartphone memungkinkan mencegah terjadinya kesalahan tindakan (Phillippi \& Wyatt, 2011). Pengembangan aplikasi smartphone dalam penilaian LKD sangat memungkinkan untuk dilakuakan (Minhajuddin, 2018). Berdasarkan hal ini peneliti tertarik untuk mengembangkan aplikasi DFUAS pada smartphone berbasi android.

\section{METODE}

Desain penelitian yang digunakan adalah perencanaan dan penelitian pengembangan (Design and Development Research). Dalam penelitian ini akan dilakukan pengembangan aplikasi smartphone DFUAS berbasis android, yang sebelumnya telah tersedia dalam bentuk paper based.

\section{HASIL}

Pengembangan aplikasi smartphone DFUAS berbasis android dilakukan dengan memberikan beberapa fitur. Fitur yang tersedia diantaranya adalah halaman login, halaman tambah data pasien, halaman pengkajian yang terdiri dari 11 item pengkajian DFUAS. Pada halaman pengkajian dilengkapi dengan panduan pengisian. Selain ini tersedia halaman database pasien.

Tampilan aplikasi DFUAS pada smartphone terdiri atas halaman awal pada halaman ini logo aplikasi DFUAS akan muncul kurang lebih 2 detik. Setelah logo menghilang, pengguna aplikasi akan diarahkan kehalaman login aplikasi (gambar 1.a). Halaman login merupakan sistem keamanan yang digunakan dalam 
aplikasi. Hanya pengguna yang memiliki username dan password yang dapat login aplikasi. Setelah pengguna mengisi username dan pasword dengan tepat, pengguna akan diarahkan kehalaman utama (home) aplikasi dan disambut dengan ucapan selamat datang pada layar (gambar 1.b). Untuk dapat mengakses seluruh fitur dalam aplikasi, pengguna cukup menyentuh icon garis tiga pada pojok kiri layar aplikasi, sehingga memunculkan pop up menu utama aplikasi (gambar 1.c).

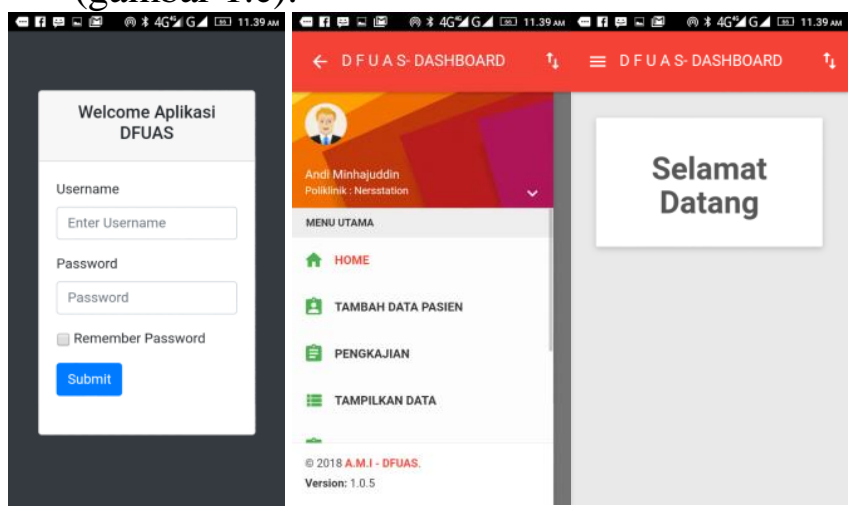

Gambar 1. Tampilan awal aplikasi.

1.a. Halaman login, 1b. Halaman utama (home) 1.c fitur aplikasi

Fitur tambah data pasien merupakan halaman yang tersedia pada aplikasi untuk menambahkan data pasien baru. Pada halaman ini pengguna mengisi form data pasien yang terdiri atas pertanyaan nama pasien, kode/MR, jenis kelamin, alamat, umur, pekerjaan, dan nomor telepon (Gambar 2). Setelah data terisi dengan lengkap dan benar, sentuh tombol input untuk menyimpan data pasien baru pada database. Pengkajian LKD pasien tidak dapat dilakukan sebelum data pasien tersimpan.
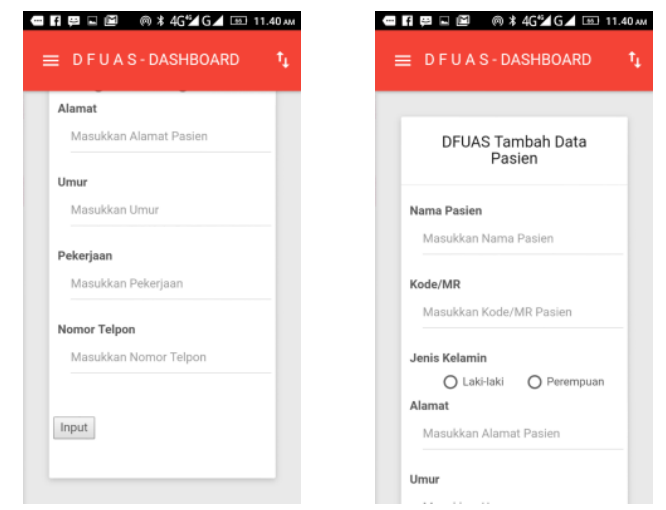

Gambar 2. Fitur tambah data pasien

Setelah data pasien tersimpan, pengkajian dapat dilakukan pada fitur pengkajian (gambar 2). Hal pertama yang harus dilakukan pengguna adalah memilih nama/inisial pasien yang telah tersimpan pada database yang akan dilakukan pengkajian LKD. Selain nama/inisial pasien, terdapat pertanyaan lain yang terdiri dari tanggal, jam, dan hari pelaksanaan pengkajian. Pada ketiga pertanyaan ini, pengguna tidak perlu mengisi karena secara otomatis akan terisi dengan waktu yang digunakan smartphone. Selanjutnya pengguna akan mengisi 11 item pertanyaan penilaian DFUAS dan diakhiri dengan menyentuh tombol input untuk menyimpan hasil penilaian yang telah dilakukan pada database pasien.
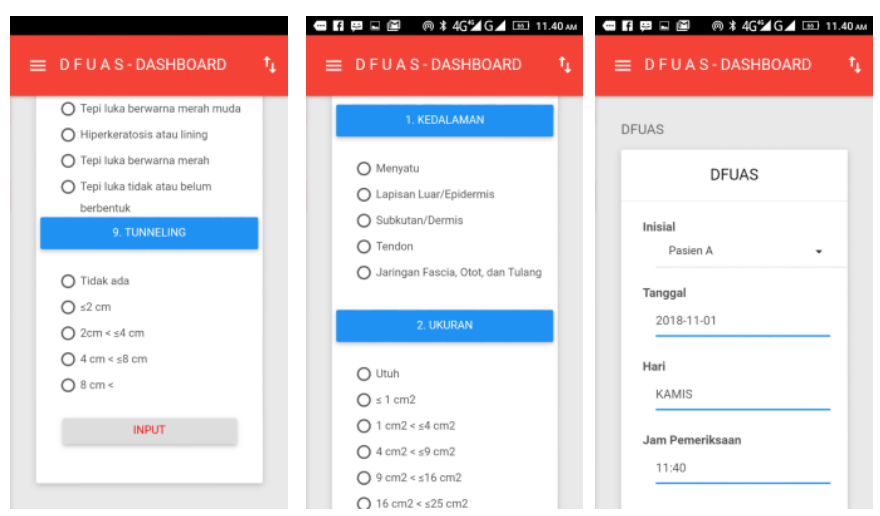

Gambar 3. Fitur pengkajian

Data hasil pengkajian pasien LKD dapat dilihat dan dievalusi pada fitur tampilkan data. Fitur ini berisi data dan hasil pengkajian setiap pasien (gambar 4). Pada fitur ini pengguna dapat mengevaluasi proses penyembuhan LKD pada pasien dengan memunculkan grafik 
penilaian. Semakin tinggi grafik, semakin buruk kondisi luka pasien. Sebaliknya grafik yang menurun, menunjukkan adanya perbaikan kondisi pada luka pasien

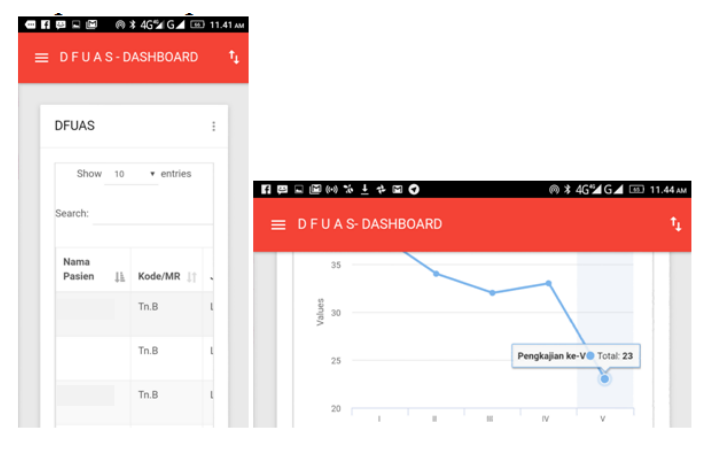

Gambar 4. Fitur tampilkan data dan grafik

\section{PEMBAHASAN}

Perkembangan teknologi informasi dalam bidang keperawatan sudah berkembang sejak lama. Berbagai macam aplikasi smartphone dalam dunia keperawatan telah dikembangkan. Bahkan berluma sejak mobile technologi masih menggunakan sistem PDA (Personal Digital Assistant). Tahun 2004 penelitian yang dilakukan oleh Choi et. al. yang melakukan pengembangan prototype aplikasi MobileNurse yang menggunakan sistem PDA bertujuan meningkatkan mobilitas sistem informasi klinis, akses terhadap informasi pasien, serta peningkatan produktivitas kerja perawat. Dari penelitian ini mengungkapkan beberapa manfaat yang didapatkan dari pemanfaatan aplikasi, diantaranya aplikasi bisa menghari Pekerjaan ganda, kualitas perawatan meningkat, informasi terkait pasien akan lebih cepat diketahui seluruh tim (Choi et al., 2004). Perkembangan teknologi informasi keperawatan terus mengalami perkembangan sampai saat ini. Perawat mulai menyadari bahwa terlibat dalam perancangan dan penerapan sistem informasi keperawatan adalah hal yang sangat penting. Sistem informasi keperawatan bukan hanya sebagai penyimpanan data, tapi mulai dari proses pengkajian sampai evaluasi dapat dimanfaatkan (Mamta, 2014). Penelitian lain yang dilakukan oleh Liu et al., (2016) mengungkapkan bahwa penggunaan smartphone efektif untuk berbagai aspek dalam dunia kesehatan, dalam pemberian asuhan keperawatan, pemberian pendidikan kesehatan, evaluasi asuhan keperawatan pasien, serta melakukan komunikasi professional antar tim kesehatan. Hasil yang lebih baik akan didapatkan dalam penggunaan aplikasi smartphone dalam dunia kesehatan dan keperawatan. Teknologi informasi keperawatan dalam kaitannya dengan penggunaan aplikasi smartphone akan terus mengalami pengembangan di masa depan.Perawat sebagai pengguna aplikasi hendaknya mengambil peran dalam perancangan dan pengembangan aplikasi. Perawat harus terus meningkatkan kemampuan dan pengetahuan dalam menggunakan aplikasi, melalui kegiatan seminar dan pelatihan.

Pengembangan aplikasi DFUAS pada smartphone yang dilakukan dengan menghadirkan beberapa fitur, menunjukkan bahwa aplikasi DFUAS smartphone lebih unggul dibandingkan dengan DFUAS paper based. Meskipun demikian, aplikasi DFUAS pada smartphone bukan berarti tidak memiliki kekurangan. Hasil penelitian tentang tentang pengembangan aplikasi pencegahan cedera berbasis smartphone (S-IPA) yang dilakukan oleh Kang et al., (2017) untuk guru yang bekerja di pusat penitipan anak, menghasilkan fakta bahwa aplikasi smartphone memiliki berbagai keunggulan. Dengan penggunaan aplikasi smartphone sistem penyampaian informasi akan lebih efektif, sehingga dapat mencegah terjadinya cedera atau luka. Aplikasi lainnya yang dikembangkan (Kummerow Broman et al., 2018) menunjukkan hasil bahwa penggunaan aplikasi smartphone dalam pengkajian luka melalui pengambilan foto dapat meningkatkan spesifitas pada objek luka dan meningkatkan kepercayaan diri observer dalam melakukan pengkajian. Kekurangan yang didapatkan adalah Buruknya deteksi SSI (Surgical Site 
Invection). Keunggulain lainnya juga diungkapkan dalam penelitian yang dilakukan oleh Santamaria \& Clayton (2000) bahwa data dan gambar luka yang telah diambil menggunakan aplikasi dapat dikirim dengan aman melalui jaringan internet untuk dikonsultasikan. Aplikasi smartphone juga dapat digunakan dilokasi terpencil. Pengembangan aplikasi pengkajian luka berbasis smartphone hendaknya dapat terus dilakukan. Dengan dilakukannya berbagai pengembangan, kemungkinan kelemahan-kelemahan aplikasi yang terdapat pada versi sebelumnya dapat diatasi.

\section{KESIMPULAN}

Adanya berbagai fitur yang tersedia pada aplikasi smartphone DFUAS, menunjukkan bahwa aplikasi smartphone DFUAS memiliki keunggulan dibandingkan dengan DFUAS versi kertas. Dengan adanya berbagai fitur yang terdapat dalam aplikasi smartphone DFUAS dapat memderikan kemudahan bagi perawat luka dalam melakukan penilaian penyembuhan LKD pada pasien DM dan memudahkan dalam pengolahan data, melalui database yang disediakan dalam aplikasi.

\section{SARAN}

Pengembangan aplikasi smartphone DFUAS dapat terus dilakukan, penambahan berbagai fitur masih diperlukan, sehingga kedepannya dapat lebih membantu perawat luka dalam melakukan penilaian penyembukan LKD pada pasien DM. Uji reliabilitas penggunaan aplikasi smartphone DFUAS berbasis android diperlukan sebelum plikasi ini benar-benar siap digunakan secara umum.

\section{DAFTAR PUSTAKA}

Arisandi, D., Yotsu, R. R., Masaru Matsumoto, Ogai, K., Nakagami, G., Tamaki, T., ... Junko Sugama.
(2016). Evaluation of Validity of The New Diabetic Foot Ulcer Assessment Scale in Indonesia. Wound Repair and Regeneration, 24(5), 876-884.

Chaiteerakij, R., Zhang, X., Addissie, B. D., Essa, A., Harmsen, W. S., Theobald, P. J., ... Snyder, M. R. (2016). Optimizing electrical impedancy myography of the tongue in ALS. Journal of Management Studies, 2-43. https://doi.org/10.1111/evo.12868.Thi $\mathrm{s}$

Choi, J., Chun, J., Lee, K., Lee, S., Shin, D., Hyun, S., ... Kim, D. (2004).

MobileNurse: Hand-held information system for point of nursing care.

Computer Methods and Programs in

Biomedicine, 74, 245-254.

https://doi.org/10.1016/j.cmpb.2003.0 7.002

Kang, K. A., Kim, S. J., Kang, S. R., Lee, S. H., Kim, Y. Y., \& Ellis, K. W. (2017). Development and Preliminary Testing of a Smartphone-Based Injury-Prevention Application (SIPA) for Teachers at Child-Care Centers in South Korea. Journal of Community Health Nursing, 34(3), 147-159.

https://doi.org/10.1080/07370016.201 7.1340767

Kummerow Broman, K., Gaskill, C. E., Faqih, A., Feng, M., Phillips, S. E., Lober, W. B., ... Poulose, B. K. (2018). Evaluation of Wound Photography for Remote Postoperative Assessment of Surgical Site Infections. JAMA Surgery, 37232, 1-8.

https://doi.org/10.1001/jamasurg.201 8.3861

Lim, J. Z. M., Ng, N. S. L., \& Thomas, C. (2017). Prevention and treatment of diabetic foot ulcers. Journal of the Royal Society of Medicine, 110(3), 104-109. https://doi.org/10.1177/01410768166 88346

Liu, Y., Ren, W., Qiu, Y., Liu, J., Yin, P., 
\& Ren, J. (2016). The Use of Mobile

Phone and Medical Apps among

General Practitioners in Hangzhou

City, Eastern China, 4(2).

https://doi.org/10.2196/mhealth.4508

Mamta. (2014). Nursing Informatics: The

Future Now. IOSR Journal of

Nursing and Health Science (IOSR-

$J N H S), 3(2), 51-53$. Retrieved from

www.iosrjournals.org

Minhajuddin, A. (2018). Penggunaan

Smartphone Dalam Pengkajian Luka

Kaki Diabetes : Literatur Review.

Jurnal Luka Indonesia, 4(3), 164-

175.

https://doi.org/10.13140/RG.2.2.1171

1.76967

Phillippi, J. C., \& Wyatt, T. H. (2011).

Smartphones in Nursing Education, 29(8), 449-454.

https://doi.org/10.1097/NCN.0b013e3

$181 \mathrm{fc} 411 \mathrm{f}$

Rasyid, N., Yusuf, S., \& Tahir, T. (2018).

Study Literatur: Pengkajian Luka

Kaki Diabetes, 4(September), 123137.

Santamaria, N., \& Clayton, L. (2000). The

Development of the Alfred/Medseed

Wound Imaging System Cleaning up.

Collegian Journal of the Royal

College of Nursing Australia, 7(4),

14-17.

https://doi.org/10.1016/S1322-

7696(08)60385-6

Wang, S. C., Anderson, J. A. E., Evans,

R., Woo, K., Beland, B., Sasseville,

D., \& Moreau, L. (2017). Point-of-

care wound visioning technology:

Reproducibility and accuracy of a

wound measurement app. Plos One, 12(8), 1-14.

Yusuf, S., Okuwa, M., Irwan, M., Rassa, S., Laitung, B., Thalib, A., ...

Sugama, J. (2016). Prevalence and

Risk Factor of Diabetic Foot Ulcers

in a Regional Hospital , Eastern

Indonesia. Open Journal of Nursing, 6(January), 1-10.

https://doi.org/10.4236/ojn.2016.6100

1 